ing of carbonate minerals ${ }^{3}$, and so does not contribute to the neutralization of carbon dioxide released from the mantle. Interaction between seawater and sea floor basalts releases a maximum flux of $2 \times 10^{14} \mathrm{~g} \mathrm{Ca}^{2+} \mathrm{yr}^{-1}$ (refs 4, 5) and leads to a net consumption of magnesium ions. So large a flux of carbon dioxide from the mantle to the ocean would therefore imply a geologically rapid accumulation of carbon dioxide in the atmosphere and ocean.

Carbon can be removed from the fluid phase and restored to the solid phase also by the incorporation of reduced organic carbon in sediments. This process is estimated to occur at a rate of $1.2 \times$ $10^{14} \mathrm{~g} \mathrm{C} \mathrm{yr}^{-1}$ (refs 3,6 ), but this flux must be largely cancelled by the rate of oxidation of old organic carbon in sedimentary rocks in order to conserve the oxygen content of the atmosphere.

There are $\sim 4 \times 10^{19} \mathrm{~g} \mathrm{C}$ in the atmosphere and ocean combined ${ }^{3}$. An unbalanced flux of carbon dioxide from the mantle to the ocean of the magnitude suggested by Javoy et al. would therefore lead to a doubling of the carbon content of ocean and atmosphere in a time of only a few hundred thousand years.

JAMES C. G. WALKER

Space Physics Research Laboratory, Department of Atmospheric and

Oceanic Science,

University of Michigan,

Ann Arbor, Michigan 48109, USA

1. Javoy, M., Pineau, F. \& Allègre, C. J. Nature 300, 171-173 (1982).

2. Meybeck, M. Rev. Géol. Dyn. Géogr. Phys. 21, 215-246 (1979)

3. Holland, H. D. The Chemistry of the Atmosphere and Oceans (Wiley-Interscience, New York, 1978).

4. Wolery, T. J. \& Sleep, N. H. J. Geol. 84, 249-275 (1976).

5. Edmond, J. M. et al. Earth planet. Sci. Lett. 46, 1-18 (1979).

6. Walker, J. C. G. Evolution of the Atmosphere (Macmillan, New York, 1977).

JAVOY ET AL. REPLY-We thank Walker for his comments which are very relevant to our article. If one wants to recycle carbon into the mantle through the sediments one has to find carriers which actually belong to the sediments and calcium carbonate is the most obvious, together with organic matter. These are the only recycled species that we have considered in our sedimentary carbon budget. However, we do not think that the values presented by Walker seriously put into question our evaluations for three reasons.

First, any evaluation of geochemical flux is subject to relatively large uncertainties as is the case for our estimates of the mantle carbon flux from the midocean rises $\left(0.58-7.2 \times 10^{14} \mathrm{~g} \mathrm{yr}^{-1}\right)$ and sedimentary carbon flux to the mantle $\left(2.8-5.6 \times 10^{14} \mathrm{~g} \mathrm{yr}^{-1}\right)$. This is also true for $\mathrm{Ca}^{2+}$ and $\mathrm{Mg}^{2+}$ fluxes from continents or from ocean floor hydrothermalism for which the values given by Walker from his refs 2-5 are true within a factor of 2 , but any better precision is doubtful.
However, we shall deal with the values as given and only correct our results because of a remark by Francheteau, who brought to our attention the calculations of Parsons ${ }^{1}$ : the lithospheric surface created and destroyed is $3 \mathrm{~km}^{2} \mathrm{yr}^{-1}$ and not $4.8 \mathrm{~km}^{2} \mathrm{yr}^{-1}$ as we stated. Hence our results have to be divided by 1.6 , giving a mean estimate of $2.44 \times 10^{14} \mathrm{~g} \mathrm{yr}^{-1}$ for the mantle carbon flux in both directions.

Second, the most important comment to make is that we cannot distinguish between the different carbon sources in the calcium carbonate present in marine sediments: we only know that a certain flux of $\mathrm{Ca}^{2+}$ and $\mathrm{Mg}^{2+}$ is carried to the oceans from continents and hydrothermal circulations. Taking the estimates given by Walker for calcium alone $(7 \times$ $10^{14} \mathrm{~g} \mathrm{yr}^{-1}$ ) we see that this can recycle $2.1 \times 10^{14} \mathrm{~g} \mathrm{yr}^{-1}$ of carbon to the sediments. With the addition of sedimentary organic carbon in the proportions given in our paper (one-third of the total sedimentary carbon) we get $3.15 \times$ $10^{14} \mathrm{~g} \mathrm{yr}^{-1}$. In a steady-state model, this recycled carbon comes from the only possible important source external to the exogenous cycle, that is, the upper mantle carbon flux $\left(2.44 \times 10^{14} \mathrm{~g} \mathrm{yr}^{-1}\right)$. These two values agree within reasonable limits. The first one is greater, which, in a steady-state model, implies that mantle contributions from sources other than mid-ocean ridges is $7 \times 10^{13} \mathrm{~g} \mathrm{yr}^{-1}$.

This type of calculation is similar to those carried out by $\mathrm{Craig}^{2}$ and Wickmann $^{3}$ in their evaluation of the ${ }^{13} \mathrm{C} /{ }^{12} \mathrm{C}$ ratio of mantle carbon, except that they did not calculate the fluxes or postulate recycling into the mantle.

Finally, it is worth pointing out that some of the carbon flux from the ridges may be incorporated directly into the mantle oceanic lithosphere, which, in our terminology, belongs to the external cycle.

We believe that continents and sea floor basalts provide enough calcium for the recycling of carbon fluxes into the mantle up to the levels we postulated in our model of the carbon geodynamic cycle. However, we thank Walker for forcing us to explain how our recycling could work.

We should like to take this opportunity to correct three other errors pointed out by Francheteau, whom we thank.

(1) In ref. 22, read La Jolla and not Paris. (2) In ref. 23, read Washington and not Paris.

(3) Uyeda and Kanamori (ref. 24) speak only of extension and compression but never of strong and weaker distension.

M. JAVOY

F. PINEAU

C.-J. Allegre

Laboratoire de Géochimie et Cosmochimie,

Institut de Physique du Globe et

Département des Sciences de la Terre,

Université Paris VI et VII, 4 Place Jussieu, 75251 Paris

Cedex 05, France

\footnotetext{
1. Parsons, B. Geophys. J. 67, 437-448 (1981).

2. Craig, H. Conf. on Nuclear Geology in Geothermal Areas, Spolet, 17-53 (1963).

3. Wickmann, E. E. Geochim. cosmochim. Acta 9, 136-153 (1956).
}

\section{Systematics of basidiomycetes based on 5S rRNA sequences and other data}

WALKER and Doolittle ${ }^{1}$ have recently suggested a fundamental redivision of the basidiomycetes on the basis of 5S rRNA sequences. They also suggested that certain morphological characteristics "are probably of independent origins" and that there are "contradictory combinations of traits involving reproductive structures and spore germination that traditionally separate the homobasidiomycetes and heterobasidiomycetes". I intend here to provide support for the basic division they propose, but also to show that there need be no contradictory combinations of traits or traits with independent origins in the basidiomycetes.

I have recently developed algorithms for reconstructing phylogenies from restriction site $^{2}$ or sequence ${ }^{3}$ data and, more important, for testing alternative phylogenetic hypotheses against one another. For sequence data, a maximum parsimony network is constructed for each variable site assuming a particular phylogeny is true, and then the procedure is repeated for an alternative phylogeny. The difference in the number of mutational events for this particular nucleotide site under the two phylogenies is then used as a score. A similar score is generated for each variable nucleotide in the data set and the resulting scores are used in a Wilcoxon matched-pair signed-rank test.

Figure 1 shows the eight species studied by Walker and Doolittle along with some of their relevant taxonomic and morphological features. Walker and Doolittle concluded that the fundamental split in this group corresponds to the clusters identified on the basis of septal pore type, as indicated in Fig. 1. I tested the significance of this fundamental division and obtained a signed-rank sum of -46 versus the most likely alternative with a sample of 45 non-zero scores. This value is so low it is not listed in the standard tables ${ }^{4}$. Consequently, the rRNA sequence data strongly support the division suggested by Walker and Doolittle. 